\title{
High-density microarray expression profiling in conventional papillary thyroid carcinomas with versus without a BRAF mutation
}

\author{
Reem Alotibi ${ }^{1,2}$, Alaa Al-Ahmadi ${ }^{1,2}$, Manar Ata ${ }^{1}$, Sajjad Karim ${ }^{1}$, Etimad Huwait ${ }^{2}$, Mamdooh Gari ${ }^{1}$, \\ Mohammad Hussain Al-Qahtani ${ }^{1}$, Hans-Juergen Schulten ${ }^{1 *}$, Jaudah Al-Maghrabi ${ }^{3,4}$ \\ From 2nd International Genomic Medical Conference (IGMC 2013) \\ Jeddah, Kingdom of Saudi Arabia. 24-27 November 2013
}

\section{Background}

Whereas $40 \%$ to $70 \%$ of papillary thyroid carcinomas (PTCs) are characterized by a BRAF mutation (BRAF ${ }^{\mathrm{mut}}$ ), unified biomarkers for the genetically heterogeneous group of BRAF wild type (BRAF ${ }^{\mathrm{wt}}$ ) PTCs are not established yet [1,2]. Using state-of-the-art technology we compared RNA expression profiles between conventional $\mathrm{BRAF}^{\mathrm{wt}}$ and BRAF ${ }^{\mathrm{mut}}$ PTCs.

\section{Materials and methods}

Affymetrix HuGene 1.0 ST microarrays were used to generate whole transcript expression profiles in 11 $\mathrm{BRAF}^{\mathrm{wt}}$ and $14 \mathrm{BRAF}^{\mathrm{mut}}$ PTCs. A p-value with a false discovery rate $(\mathrm{FDR}) \leq 0.05$ and a fold change $>2$ were used as a threshold of significance for differential expression. Spearman's correlation as a similarity matrix was utilized for unsupervised two dimensional hierarchical clustering. The BRAF mutational status was surveyed by direct sequencing the hotspot region of BRAF exon 15.

\section{Results}

Hundred eighty transcripts from annotated genes were significantly differentially expressed between $\mathrm{BRAF}^{\mathrm{wt}}$ and BRAF $^{\text {mut }}$ PTCs and unsupervised cluster analysis was able to separate both groups. The most significantly upregulated genes in $\mathrm{BRAF}^{\text {mut }}$ compared to BRAF ${ }^{\mathrm{wt}}$ PTCs include transmembrane 7 superfamily member 4 (TM7SF4, located on 8q23), glutaminase 2 (GLS2; 12q13), ladinin 1 (LAD1; 1q25.1-q32.3), TBC1 domain family, member 2 (TBC1D2; 9q22.33), chromosome
19 open reading frame 33 (C19orf33; 19q13.2), keratin 19 (KRT19; 17q21.2), and poliovirus receptor-related 4 (PVRL4; 1q22-q23.2). The most downregulated genes in BRAF $^{\text {mut }}$ PTCs include inositol 1,4,5-triphosphate receptor, type 1 (ITPR1; 3p26-p25), leucine rich repeat and Ig domain containing 2 (LINGO2; 9p21.2-p21.1), solute carrier family 26 , member 4 (SLC26A4: 7q31), deiodinase, iodothyronine, type I (DIO1; 1p33-p32), and hepatic leukemia factor (HLF; 17q22). Among differentially expressed microRNAs, mir492 was highly upregulated in BRAF ${ }^{\text {mut }}$ PTCs.

\section{Conclusions}

This study provides a detailed overview of differentially expressed genes between BRAF $^{\mathrm{wt}}$ vs. BRAF ${ }^{\text {mut }}$ conventional PTCs using whole transcript, high-density microarrays. Valuable candidate genes shall be assessed further to identify molecular pathways and molecular biomarkers which distinguish BRAF $^{\mathrm{wt}}$ from BRAF ${ }^{\mathrm{mut}}$ PTCs.

This study was supported by King Abdulaziz City for Science and Technology (KACST) grants 09-BIO707-03 and 09-BIO820-03.

\section{Authors' details \\ ${ }^{1}$ Center of Excellence in Genomic Medicine Research, King Abdulaziz University, Jeddah, Kingdom of Saudi Arabia. ${ }^{2}$ Department of Biochemistry, King Abdulaziz University, Jeddah, Kingdom of Saudi Arabia. ${ }^{3}$ Department of Pathology, Faculty of Medicine, King Abdulaziz University, Jeddah, Kingdom of Saudi Arabia. ${ }^{4}$ Department of Pathology, King Faisal Specialist Hospital and Research Center, Jeddah, Kingdom of Saudi Arabia.}

Published: 2 April 2014

\footnotetext{
* Correspondence: hschulten@kau.edu.sa

'Center of Excellence in Genomic Medicine Research, King Abdulaziz

University, Jeddah, Kingdom of Saudi Arabia

Full list of author information is available at the end of the article
}

(c) 2014 Alotibi et al; licensee BioMed Central Ltd. This is an Open Access article distributed under the terms of the Creative Commons 


\section{References}

1. Lee JH, Lee ES, Kim YS: Clinicopathologic significance of BRAF V600E mutation in papillary carcinomas of the thyroid: a meta-analysis. Cancer 2007, 110:38-46.

2. Rusinek D, Szpak-Ulczok S, Jarzab B: Gene expression profile of human thyroid cancer in relation to its mutational status. Journal of molecular endocrinology 2011, 47:R91-103.

doi:10.1186/1471-2164-15-S2-P21

Cite this article as: Alotibi et al.: High-density microarray expression profiling in conventional papillary thyroid carcinomas with versus without a BRAF mutation. BMC Genomics 2014 15(Suppl 2):P21.

Submit your next manuscript to BioMed Central and take full advantage of:

- Convenient online submission

- Thorough peer review

- No space constraints or color figure charges

- Immediate publication on acceptance

- Inclusion in PubMed, CAS, Scopus and Google Scholar

- Research which is freely available for redistribution

Submit your manuscript at www.biomedcentral.com/submit
Ciomed Central 